\title{
Transurethraal inbrengen van magneetkralen voor seksuele stimulatie: twee patiënten
}

\author{
Marc Deelen $^{1}$ Tom A. T. Marcelissen ${ }^{1} \cdot$ Jamie M. Drossaerts $^{1} \cdot$ Esther E. G. Remijn $^{2} \cdot$ Kees van de Beek $^{1}$
}

Published online: 19 September 2016

(C) The Author(s) 2016. This article is an open access publication.

Samenvatting Urethraal inbrengen van magneetkralen is een weinig beschreven fenomeen, dat vooral gezien wordt bij met name jonge mannen. De voornaamste reden is het verkrijgen van seksueel genot. Recentelijk werden twee jonge mannelijke patiënten gezien die een reeks magneetkralen in de urethra brachten voor seksuele stimulatie. Vanwege magnetisme kan het transurethraal verwijderen van deze kralen lastig zijn. Corpora aliena in de blaas kunnen LUTS of urineweginfecties veroorzaken. Echter, vanwege schaamte zal niet elke patiënt spontaan deze seksuele handeling vermelden. Bij jonge mannen met LUTS of recidiverende urineweginfecties dient men dus alert te zijn op een corpus alienum.

Trefwoorden seksuele stimulatie corpus alienum blaas magneetkralen

\section{Transurethral inserted magnetic beads for sexual stimulation: two patients}

Abstract Urethral insertion of magnetic beads is sporadically described in literature and is reported in mostly young males. The primary reason for this act, is sexual pleasure. Recently, two cases of young males were seen, who inserted a magnetic bead string in the urethra for sexual stimulation. Due to magnetism, transurethral removal of these beads can be difficult. Foreign bodies in the bladder could cause LUTS

Marc Deelen

marc.deelen@hotmail.com

afdeling Urologie, Maastricht UMC+, Maastricht, Nederland

2 afdeling Urologie, Slingeland ziekenhuis, Doetinchem, Nederland or urinary tract infections. However, not all patients will report this sexual act due to embarrassment. Therefore, one should consider a foreign body as a primary cause of LUTS or recurrent urinary tract infections in young males.

Keywords sexual stimulation - foreign bodies bladder . magnetic beads

\section{Introductie}

Recentelijk presenteerde zich in twee verschillende centra een patiënt met transurethraal ingebrachte magneetkralen. Het transurethraal inbrengen van corpora aliena, in combinatie met masturbatie of coïtus, zorgt mogelijk voor een toename van seksuele stimulatie. Er worden twee casus besproken en een overzicht gegeven van de recente literatuur over de extractie van deze magneetkralen.

\section{Casus 1}

In het Maastricht UMC+ werd op de polikliniek Urologie een 17-jarige gezonde jongeman gezien, die was doorverwezen door de huisarts met dysurie en hematurie bij een urineweginfectie. De huisarts startte in eerste instantie antibiotische behandeling, echter, na enkele weken keerden de klachten terug. Bij doorvragen vermeldde de patiënt dat hij zes weken daarvoor meerdere magneetkralen via de urethra had ingebracht, met als beweegreden seksuele stimulatie uit te lokken. De patiënt dacht de kralen spontaan te kunnen lozen. Hij had in het geheel geen klachten van de kralen gehad, tot de urineweginfectie was opgetreden. Hij voelde alleen 'iets' kantelen in zijn onderbuik bij bukken. Bij röntgenonderzoek werd een cluster van bolvor- 


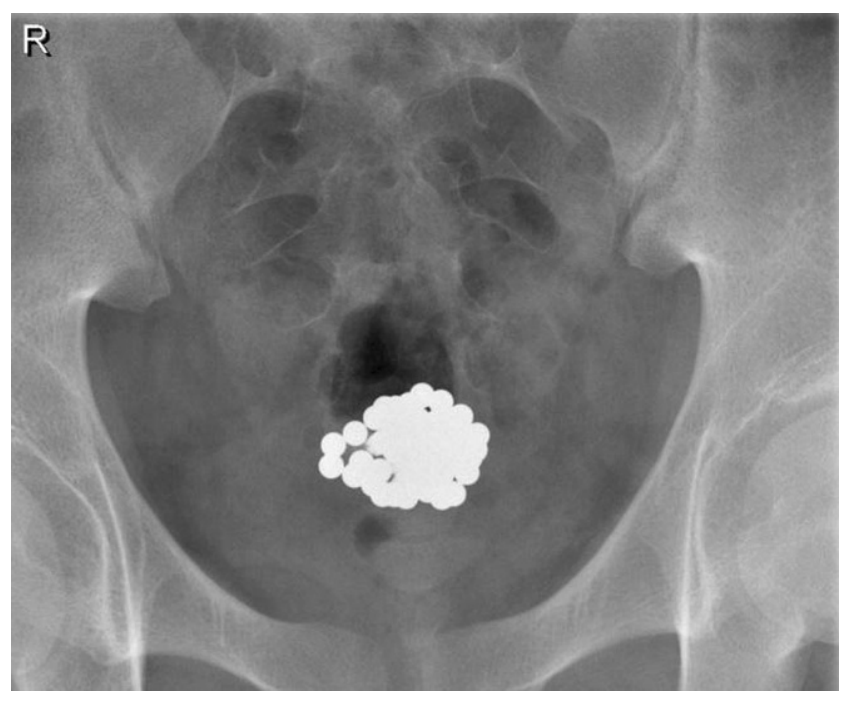

Figuur 1 Röntgenfoto van het bekken waarop ter hoogte van de blaas een cluster bolvormige metaalhoudende corpora aliena te zien is.

mige metaalhoudende corpora aliena gezien ter hoogte van de blaas (fig. 1). Op de operatiekamer is initieel gepoogd om de magneetkralen transurethraal te verwijderen middels een paktang (Storz) met twee rechte bekdelen. Pogingen in een magneetkraal te isoleren van het geclusterde geheel faalde echter vanwege de magnetische kracht van de kralen. Bovendien raakte het instrumentarium zelf gemagnetiseerd. $\mathrm{Na}$ demagnetisatie van het instrumentarium, werd een sectio alta uitgevoerd. Er werden in totaal 57 magneetkralen verwijderd, met een individuele diameter van $5,0 \mathrm{~mm}$ (fig. 2).

\section{Casus 2}

In het Slingeland Ziekenhuis te Doetinchem werd een 21jarige gezonde jongeman gezien op de Spoedeisende Hulp rond 6:00 uur in de ochtend, met hevige urgency. Hij vertelde de avond ervoor magneetkralen te hebben ingebracht in zijn urethra voor seksuele stimulatie. Ondanks pogingen van de patiënt zelf, lukte het hem maar deels om de magneetkralen te verwijderen. Bij röntgenonderzoek werden metaalhoudende corpora aliena gezien ter hoogte van de urethra prostatica (fig. 3). Een poging tot poliklinische evacuatie van de kralen met een flexibele cystoscoop, was niet succesvol. Dezelfde dag werd de patiënt op de operatiekamer behandeld, waarbij met een resectoscoop, onder zicht, de magneetkralen werden gezien in de urethra prostatica. Er werd voor gekozen om de magneetkralen door te duwen tot in de blaas, omdat er in de urethra onvoldoende grip op de magneetkralen kon worden gekregen. Vanuit de blaas lukte het wel om de magneetkralen te verwijderen, zij het met enige moeite. Het was lastig om de kralen een voor een op te pakken, omdat deze aan de cystoscoop bleven 'hangen', door hun magnetische werking. Er werd gebruikgemaakt van een paktang (Olympus) met twee ronde bekdelen (fig. 4). Uiteindelijk zijn alle 49 kralen, met een diameter van 5,5 mm elk, transurethraal verwijderd, waarbij geen blijvende schade is opgetreden.

\section{Discussie}

Levine et al. raden aan om bij een patiënt die zich met LUTS presenteert op SEH ook een corpus alienum in de differentiaaldiagnose op te nemen, ondanks het feit dat een corpus alienum een zeldzaamheid is [1]. Van Ophoven en deKernion beschreven, op basis van een uitgebreide review, dat de verwijdering van corpora aliena in de urethra en blaas afhangt van de grootte en beweeglijkheid van deze corpora aliena [2]. De peniele urethra heeft een doorsnede van 5-6 mm. Daarnaast zijn er drie fysiologische vernauwingen van de mannelijke urethra, namelijk de urethra prostatica, de urethra membranacea en de meatus externus. Zijn de magneetkralen bij inbrengen eenmaal de meatus externa en urethra membranacea gepasseerd, dan is op basis van de lo-
Figuur 2 Chirurgische verwijdering van 57 magneetkralen.

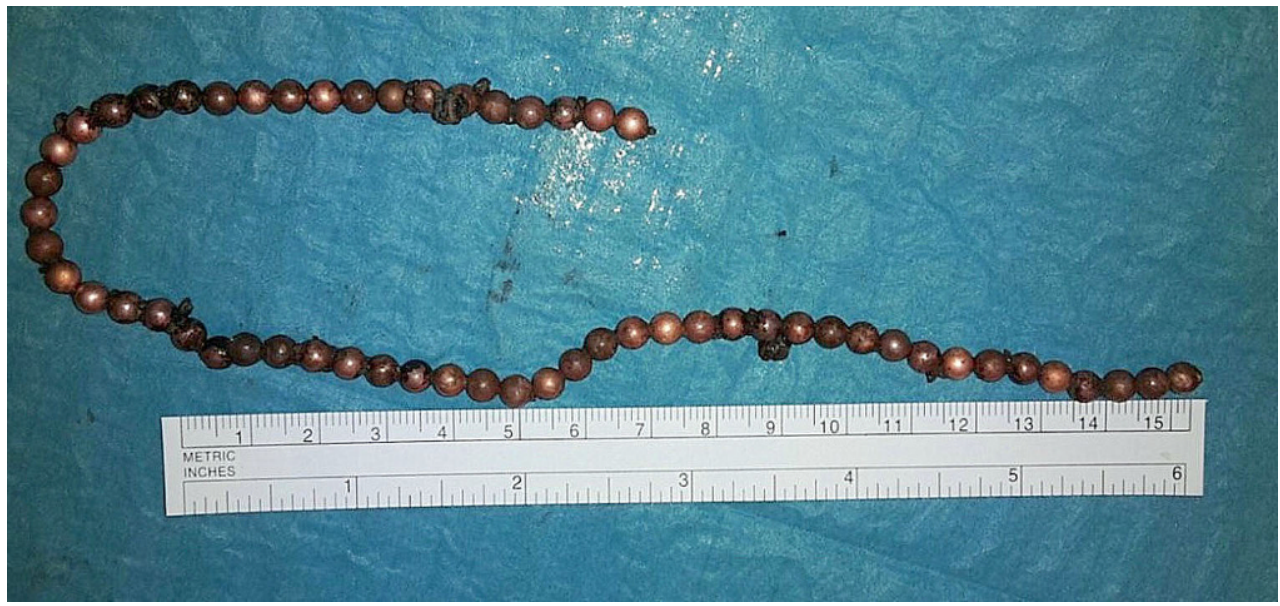




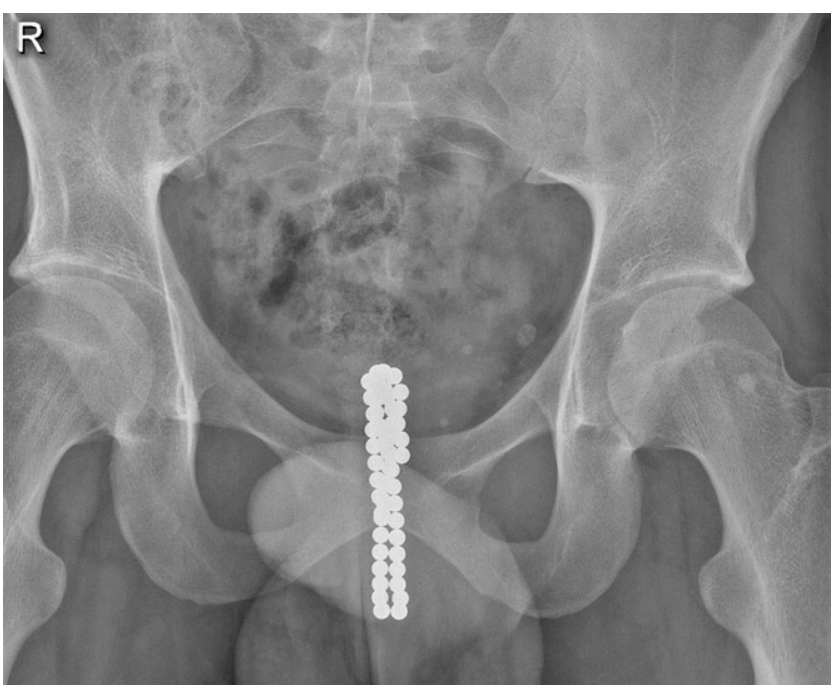

Figuur 3 Röntgenfoto van het bekken waarop, ter hoogte van de urethra prostatica, een reeks metaalhoudende corpora aliena te zien is.

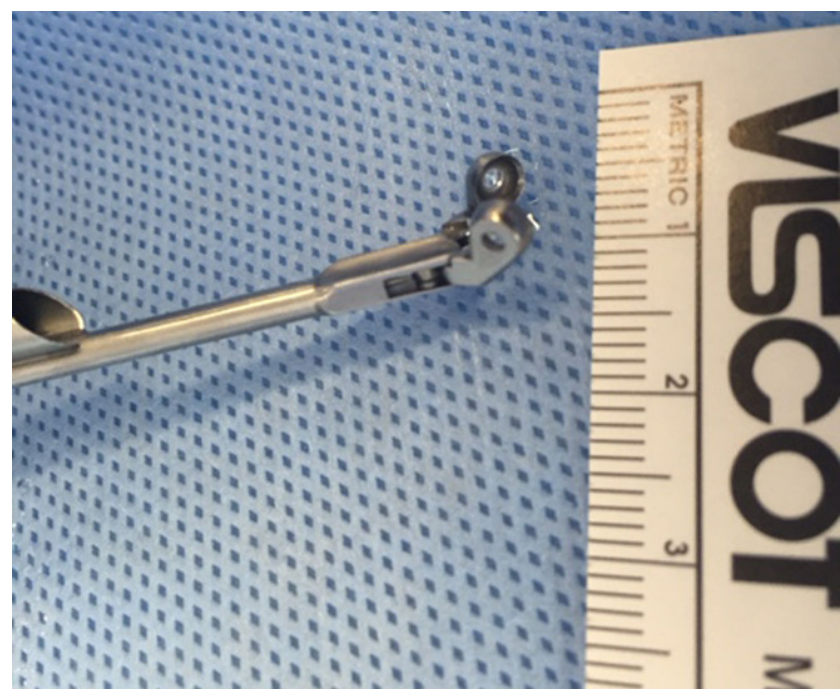

Figuur 4 Paktang met ronde bekdelen (Olympus A207 12 A).

Tabel 1 Overzicht van diverse benaderingen ter verwijdering van de magneetkralen.

\begin{tabular}{|c|c|c|c|c|c|}
\hline studie & $\begin{array}{l}\text { patiënt- } \\
\text { karakteristieken }\end{array}$ & $\begin{array}{l}\text { aantal } \\
\text { kralen }\end{array}$ & $\begin{array}{l}\text { diameter } \\
\text { kraal }\end{array}$ & $\begin{array}{l}\text { geslaagde } \\
\text { extractie }\end{array}$ & omschrijving extractie \\
\hline Levine et al. [1] & $\begin{array}{l}\text { 30-, 42-, 43-jarige } \\
\operatorname{man}(n=3)\end{array}$ & - & - & open & $\begin{array}{l}2 \text { casus geconverteerd naar sectio alta, } \\
1 \text { direct sectio alta }\end{array}$ \\
\hline Graziottin et al. [4] & $\begin{array}{l}\text { 22-jarige man } \\
(n=1)\end{array}$ & 29 & $6 \mathrm{~mm}$ & transurethraal & transurethrale verwijdering met paktang \\
\hline Ellimoottil et al. [6] & $\begin{array}{l}\text { 11-jarige jongen } \\
(n=1)\end{array}$ & 24 & $3 \mathrm{~mm}$ & transurethraal & $\begin{array}{l}\text { kinder cysto-urethroscoop met standaard } \\
\text { paktang en steenbasket }\end{array}$ \\
\hline Pieretti et al. [7] & $\begin{array}{l}\text { 16-jarige jongen } \\
(n=1)\end{array}$ & 25 & - & open & $\begin{array}{l}\text { conversie naar sectio alta, na endoscopi- } \\
\text { sche pogingen met meerdere paktangen en } \\
\text { steenbaskets }\end{array}$ \\
\hline Robey et al. [8] & $\begin{array}{l}\text { 12-jarige jongen } \\
(n=1)\end{array}$ & 30 & $5 \mathrm{~mm}$ & minimaal-invasief & $\begin{array}{l}\text { percutane verwijdering met nefroscoop en } \\
\text { paktang }\end{array}$ \\
\hline Zeng et al. [9] & $\begin{array}{l}21 \text {-jarige man } \\
(n=1)\end{array}$ & 125 & $3 \mathrm{~mm}$ & transurethraal & $\begin{array}{l}\text { transurethrale extractie met een F9,5 ure- } \\
\text { terale access sheath, met op de tip } 1 \text { ge- } \\
\text { fixeerde kraal }\end{array}$ \\
\hline $\begin{array}{l}\text { huidige studie, } \\
\text { casus } 1\end{array}$ & $\begin{array}{l}\text { 17-jarige jongen } \\
(n=1)\end{array}$ & 57 & $5,0 \mathrm{~mm}$ & open & $\begin{array}{l}\text { geconverteerd naar sectio alta, na trans- } \\
\text { urethrale poging met paktang } \\
\text { (rechte bekdelen) }\end{array}$ \\
\hline $\begin{array}{l}\text { huidige studie, } \\
\text { casus } 2\end{array}$ & $\begin{array}{l}21 \text {-jarige man } \\
(n=1)\end{array}$ & 49 & $5,5 \mathrm{~mm}$ & transurethraal & $\begin{array}{l}\text { transurethrale verwijdering met paktang } \\
\text { (ronde bekdelen) }\end{array}$ \\
\hline
\end{tabular}

catie, spontane lozing zeer onwaarschijnlijk, zoals zichtbaar is in fig. 3 .

Het inbrengen van corpora aliena transurethraal is op zich niet uniek. Recentelijk rapporteerden Campschroer en collega's in dit tijdschrift over het fenomeen urethral sounding, oftewel recreatief urethraal sonderen voor seksueel genot [3]. De meest voorkomende reden voor het transurethraal inbrengen van corpora aliena is seksuele bevrediging $[4,5]$. Er is wereldwijd in de medische literatuur maar van acht patiënten een casus gepubliceerd over magneetkralen. Deze mannen, met een leeftijd van 11-43 jaar, brachten transurethraal in totaal 24-125 magneetkralen in
[1, 4, 6-9]. De behandeling in de verschillende situaties bestond uit extractie via endoscopische, minimaal invasieve of open chirurgie (tab. 1).

Levine et al. beschreven een serie met drie patiënten, van wie er twee een sectio alta ondergingen nadat eerdere endoscopische behandeling had gefaald [1]. De derde patiënt uit deze serie onderging direct een open verwijdering van de kralen, vanwege blaasretentie en omdat endoscopische benadering bij de voorgaande patiënten had gefaald. Pieretti et al. beschreven in 2014 een casus waarbij een 16jarige jongeman 25 magneetkralen had ingebracht tijdens masturbatie voor extra stimulatie [7]. Ondanks pogingen 
om de kralen te verwijderen met paktangen en steenbaskets, was een sectio alta nodig om alle kralen te verwijderen. Robey et al. beschreven een percutane cystotomie bij een 12-jarige jongen, bij wie met een nefroscoop eenvoudig 27 magneetkralen werden verwijderd met een paktang [8]. Zeng et al. beschreven een alternatieve techniek voor endoscopische extractie van de magneetkralen, waarbij ze één $3 \mathrm{~mm}$-magneetkraal stevig hadden gefixeerd in het uiteinde van een F9,5-ureterale access sheath [9]. De patiënt werd in steensnedeligging geopereerd onder algehele anesthesie. Vervolgens werd een F22 rigide cystoscoop transurethraal ingebracht. Pogingen om de kralen met een tang te pakken mislukte door het gladde oppervlak van de kralen en de magnetische aantrekkingskracht van de kralen onderling. Daarna werd de access sheath met een gefixeerde magneetkraal via de cystoscoop ingebracht tot in de blaas. Op deze manier kostte het slechts vijf minuten om alle 125 kralen succesvol endoscopisch te verwijderen, in een tempo van vijf tot vijftien kralen per keer.

De twee casus in onze serie zijn vergelijkbaar wat betreft leeftijd van de patiënt en het verwijderingsmechanisme. Toch lukte het in casus 1 niet om de kralen endoscopisch te verwijderen, en in casus 2 wel. Hiervoor is een aantal mogelijke verklaringen te bedenken. Bij de patiënt in casus 2 vormden de magneetkralen een snoer in de urethra prostatica, terwijl in casus 1 de magneetkralen zich geclusterd in de blaas bevonden, waarbij roestvorming was opgetreden, omdat de kralen daar al langere tijd zaten. In casus 2 werd gebruikgemaakt van een paktang met ronde bekdelen, en daarmee een groter contactoppervlak, waardoor de magneetkralen mogelijk makkelijker te verwijderen waren. Daarnaast kan uiteraard ook de techniek of ervaring van de operateur een rol hebben gespeeld.

\section{Conclusie}

De behandeling van transurethraal ingebrachte magneetkralen kan een uitdaging zijn. Het gebruik van magneetkralen voor seksuele stimulatie wordt vooral gezien bij jonge mannen. Endoscopische extractie van deze kralen is niet eenvoudig vanwege het magnetische karakter van de kralen. Een kleinere kraaldiameter $(3 \mathrm{~mm})$ lijkt bij te dragen aan de kans op succes, evenals het gebruik van een paktang met ronde bekdelen. Gezien de hoge kans op conversie, kan laagdrempelig een sectio alta overwogen worden.

Open Access This article is distributed under the terms of the Creative Commons Attribution 4.0 International License (http:// creativecommons.org/licenses/by/4.0/), which permits unrestricted use, distribution, and reproduction in any medium, provided you give appropriate credit to the original author(s) and the source, provide a link to the Creative Commons license, and indicate if changes were made.

\section{Literatuur}

1. Levine MA, Evans H. Open removal as a first-line treatment of magnetic intravesical foreign bodies. Can Urol Assoc J. 2013;7:25-8.

2. Ophoven A van, Kernion JB de. Clinical management of foreign bodies of the genitourinary tract. J Urol. 2000;164:274-87.

3. Campschroer T, Holzhauer C, Rijpsma D, et al. Urethral sounding: a risky sex game. Tijdschr Urol. 2016;6:21-3.

4. Graziottin TM, Freitas GSD de, Da Ros CT, et al. Magnetic spheres as foreign body into the bladder. J Sex Med. 2013;10:2590-2.

5. Stravodimos KG, Koritsiadis G, Koutalellis G. Electrical wire as a foreign body in a male urethra: a case report. J Med Case Rep. 2009;3:49.

6. Ellimoottil C, Faasse MA, Lindgren BW. Endoscopic management of transurethrally inserted magnetic beads. Urology. 2013;81:13-4.

7. Pieretti RV. High-strength neodymium magnetic beads: a rare foreign body in the bladder of an adolescent. Urol Case Rep. 2014;2:145-6.

8. Robey TE, Kaimakliotis HZ, Hittelman AB, et al. An unusual destination for magnetic foreign bodies. Pediatr Emerg Care. 2014;30:643-5.

9. Zeng SX, Li HZ, Zhang ZS, et al. Removal of numerous vesical magnetic beads with a self-made magnetic sheath. J Sex Med. 2015;12:567-71.

drs. Marc Deelen semi-arts urologie

dr. Tom A.T. Marcelissen aios urologie

drs. Jamie M. Drossaerts anios urologie

drs. Esther E. G. Remijn uroloog

drs. Kees van de Beek uroloog 